suggest the interpretation that Nature expresses a purpose, and that since the scientifically known system of Nature, being largely unconscious, cannot be credited with a purpose, we are led to think of a Creator's purpose. The fact that the scientific ideal is limited to a naturalistic description does not in the least imply that we need refrain from idealistic, transcendental, mystical, or religious interpretationthe only kind of interpretation there is. The second lecture dealt with the disharmonies in Nature and the difficulties to which they give rise in the teleological interpretation of a Creator's world, but such disharmonies, often exaggerated, need not obscure the greater fact of an overriding harmony. The final lecture, on "Lessons from Evolution", based on the fact of a real progress in organic evolution, is a plea for a ranging of human endeavour in line with the trends which have been conspicuously progressive in the re-human ascent of life.

\section{Control of Canadian Insect Pests}

The Canadian Government and the Empire Marketing Board are jointly financing a search in Europe for the parasites of certain Canadian insect pests. The Canadian Department of Agriculture has asked the help of the Parasite Breeding Laboratory at Farnham Royal, Bucks, which is maintained by the Empire Marketing Board, in combating the present severe outbreak of a forest insect, Diprion polytomum, and also in fighting the plague of balsam woolly aphis, which is causing serious injury to balsam fir in the Maritime Provinces. If the balsam woolly aphis infection spreads throughout the eastern forests, as it threatens to do, enormous losses in pulpwood will result. The only hope seems to lie in the introduction of a parasite to check the advance of the aphis. The pest came originally from Europe, but it is not common, and an intensive search will have to be made in Central Europe to find its insect parasites. These insects will then be brought to England and bred up at the Farnham Royal laboratories. Nearly one million insect parasites have been bred and dispatched from time to time from Farnham Royal to all parts of the Empire. The wheat-stem sawfly, one of the Western farmers' major problems, is now being investigated. Officers of the Imperial Institute of Entomology have collected parasites in France and bred them up in England. Last season several large consignments of broken wheat straw, containing saw. flies plus parasites, were packed in special boxes and shipped to Canada. These parasites have been released in the wheatfields, and up to date are doing well.

\section{Blanching of a Bay Horse}

In the Field for April 16, p. 582, Miss J. McAlpine gives an account of a bay horse the mane of which, black as usual in this colour, turned nearly white owing to a severe fright it received at six years of age when out at grass in a very long field. An aviator, in trying to land here, drove the horse the whole length of the field, and nearly alighted on it. No one saw the horse for three days afterwards, but it was then found to have lost the colour of its mane, as described, while the tail had also become quite grey. A photograph of the animal, now nine years old, accompanies the note, and shows the pale mane very plainly, so that the effect of the shock seems to have been permanent. The writer of this note once casually saw in a London street a bay pony with a grey mane and also an angular grey patch let in, as it were, on the brown short hair of the neck, but put it down to a freak of variation. The horse is more liable to variation in pelage than any other domestic mammal, and another bay, an aged van-horse, also seen casually in London, was spotted with white over the brown parts as clearly as any deer, but with smaller, more angular spots.

\section{Frequency of Insects in the Air}

Among a recent series of "Why the Weather" articles by C. F. Talman, issued by Science Service, there is one article commenting on some experiments made in France by A. Bonnet to determine what that meteorologist called the 'entomological density' of the air, a few feet above the ground. This quantity, defined as the number of insects in a cubic metre, was obtained by means of a muslin net attached to the front of a motor car. The car was driven for a kilometre in unfrequented regions far from places where insects collect in exceptional numbers, and the insects in a 1000 cubic metre sample of air were collected and counted. The density was found generally to vary from one or two at sunrise to about seventy in the early afternoon, with a subsequent decline to one or two again at sunset. Those species normally found only very early and late tended to appear in the middle of the day when the air was nearly saturated. This is a line of research that might appeal to motoring meteorologists. It would be interesting to trace the effect of the insect density upon visibility, and see to what extent some of our midsummer hazes are due to large values of this quantity.

\section{Orthographical Relief}

A NEW method of showing surface relief on a topographical map is described by Prof. T. Kitirô in the Geographical Journal for March. The inventor claims this to be a natural, in contrast to a conven. tional, method, since it is based on the principle of shading, and gives the reader the appearance of the land rather than detached information of heights. The method makes use of what Prof. Kitirô calls the ' inclined contour'. This is defined as the projection upon a datum plane of the outline of the intersection of the ground surface with an inclined plane. By contrast, the ordinary contour, which is distinguished as the horizontal contour, is the projection upon a datum plane of the intersection line of the ground surface with a horizontal plane. The inclination of the inclined plane is assumed to be $45^{\circ}$. The effect of these inclined contours is to give a shaded map of relief features with a southern illumination on the specimen of a Japanese map which is reproduced. The thickness of the inclined contours is constant, and after experiment it was found most useful to have between thirty and seventy lines to the centimetre.

$$
\text { No. 3262, VoL. 129j }
$$


The method of drawing these contours from the ordinary contoured map is fully described. One obvious disadvantage is that they give a dark map, but this might be overcome by drawing the contours in grey or buff. The finished map certainly gives a striking picture of relief where the slopes are steep.

\section{Sugar Cane Research}

THE Report of the proceedings of the Imperial Sugar Cane Research Conference, held in London in July 1931 , has recently been issued by H.M. Stationery Office (price 2s. 6d. net). The conference, to which reference has already been made in NATURE (July 25, p. 160) was convened by the Empire Marketing Board to discuss the future of scientific research in sugar cane production, but it was decided that the world economic position should be considered in drawing up a research programme. As a result, some seventy pages of the report give a review of the economic position of the industry, which contains many valuable facts and figures. The present organisation of research within the British Empire is considered in some detail in reference to the various cane sugar growing areas, after a brief general introduction by Dr. P. S. Hudson that deals mainly with the genetical side of the problem. Dr. Hudson concludes that whilst some early advances have been made, and still may be expected, the full utilisation of scientific methods in breeding, which involves a cytological study of the genetical material, can alone lead to continued progress and development in this line of work, which is of so much importance in developing Empire resources. Dr. W. R. Thompson points out that, owing to the wide range of habitat in which sugar cane can be successfully grown, it suffers from an unusually large list of insect parasites. With some of these, such as the leaf froghopper in Hawaii, a very great measure of success in combating them has been obtained by using the method of biological control. Dr. Thompson states that the method of biological control has this great advantage that, when it can be successfully applied, it provides what is practically permanent relief at a relatively small initial cost.

\section{Evaluating Periodicities by Machinery}

THE application of Fourier's harmonic analysis to weather phenomena has revealed many outstanding periodicities. To those who feel that the next step should be directed towards understanding the cause of these periodicities, rather than the evaluation of yet more, the invention of mechanical aids to 'periodicity hunting', such as Abbot's periodometer, will naturally make little appeal (Smithsonian Miscell. Coll., vol. 87, No. 4 (Pub. 3138): "The Periodometer, an Instrument for Finding and Evaluating Periodicities in Long Series of Observations"'. By Dr. C. G. Abbot). The device is one for avoiding numerical computation in studies of this kind. It does not detect periodicities; that has to be done by inspection of the statistical material. This step involves a personal factor. Given any suspected periodicity, the machine shows to what extent this appears consistently throughout the material, and determines the shape of the curve of variation of the element over this period. The reality of the periodicity is judged from the shape of this curve. Having decided that it is real, the operator is then able, with the aid of the machine, to eliminate this periodic variation, and so gets a residual curve that is scrutinised afresh for other periodicities. The curve of variation may depart widely from a simple sine curve, and this method of analysis therefore differs from the classical Fourier process, and on account of the presence of the personal factor will give different results when different workers use the same material. The ultimate test of merit is, of course, whether the method will lead to greater knowledge of underlying physical causes, and it remains to be seen whether this will be the case. The cost of production of the first periodometer was apparently a thousand dollars, the money being provided by the Research Corporation of New York.

\section{Chemistry and Action of Drugs}

IN his Lane Lectures on pharmacology, Prof. W. Straub, of Munich, discusses certain problems of general interest in the chemistry, synthesis, and action of drugs (Stanford University Publications : University Series: Medical Sciences, vol. 3, No. 1, 1931 ; London: Humphrey Milford). Two are devoted to digitalis, the chemistry of the glucosides of the leaf and their physiological action being reviewed. Prof. Straub points out that the differences in action of the glucosides of the cardiac tonies, digitalis, strophanthus, and squill, can be explained to a great extent by a knowledge of the speed with which they are taken up by the tissues of the body as well as by the heart, and of the ease or difficulty with which they can be afterwards destroyed. The greater response of the pathological, as compared with the normal, heart to digitalis can be similarly explained, since the slowing of the circulation permits of a greater $a b$. sorption of the drug by the tissues. These lectures were primarily addressed to pharmacologists. Three subjects were chosen as of interest to students and physicians; anæsthesia, the pharmacology of the heavy metals, and the camphor problem. In the latter lecture Prof. Straub discusses the attempts made to prepare a synthetic compound having similar stimulant effects to camphor on a failing heart and respiration without its disadvantage of slow absorption after injection. Cardiazole (pentamethyl. ene tetrazole) appears to fulfil the requirements best at the present time; it is more soluble in water than in oil, so that it will be rapidly absorbed, but its oil insolubility will ensure that it exerts a stimulant rather than a narcotic action on the central nervous system. The sixth lecture, addressed to a scientific audience without medical interests, dealt with certain general problems of the use of intoxicating drugs.

\section{Reconstruction of Tokyo and Yokohama}

DURING the seven years that followed the great earthquake of Sept. 1, 1923, the rebuilding of Tokyo and Yokohama was practically completed, at a cost of nearly eighty-five million pounds. M. Jean Gracy has written a full account of the renovated cities, of 